\title{
Editorial
}

\section{Two Hundred Issues Later: The Dream Comes True}

It seems as if it were yesterday that we launched the Journal of Alzheimer's Disease (JAD). However, in reality, it has been over one and a half decades, and in that time, the journal has published over 40 volumes, made up of 200 issues.

When we organized the JAD, it was our original goal to establish a quality journal that would facilitate communication of new and original ideas and results concerning disorders of the central nervous system associated with symptoms and pathology described by Alzheimer. In addition, we envisaged a journal that would complement the existing Alzheimer's disease journals that cater primarily to "mainstream" concepts, ideas, and approaches.

JAD has more than met our expectations in its publication of numerous important research and review contributions and its participation in meetings and symposiums as well as encouragement of outstanding authors, exemplified by its Alzheimer Award program. These results have been achieved through the hard work of the Editors-in-Chief, Mark Smith and George Perry; Managing Editor, Beth Kumar; the deputy, senior, and associate editors; and, of course, the researcher authors.

Drs. Smith and Perry took over as Editors-in-Chief soon after the founding of this journal. In addition to the tasks of recruiting researchers to submit papers, they faced the task of finding a stable source of funding and organization to support the journal before all of the initial funding was disbursed. The choice of IOS Press has proven to be synergistic and important in the ever-changing milieu of scientific publication. This is particularly true with the need to make research papers supported by public funds freely available soon after publication.

As the founding Editor, I was impressed with the way JAD reviewed and managed the publication of paper that I wrote by imagining how the fictional super detective, Sherlock Holmes, might approach finding a cause of the morbidity and mortality associated with the entity we call Alzheimer's disease. In ensuing analysis, I found a new possible culprit, a toxin coded for by a bacterial virus gene (the diphtheria toxin). This suggestion was far from the mainstream but JAD, in accord with its founding principles (and positive comments from its reviewers), published it so that it might function to stimulate a new line of thought and possible research.

We predict that role of this journal will become more important: as analysis of the ever growing genomic database is employed to identify factors associated with Alzheimer's disease, studies of the brain connectome, which are enhancing our understanding of brains structures and function, and applications from potential anti-aging studies such as the recent parabiotic experiments in which older mice began to replace brain, heart, and skeletal muscle cells following surgical procedure which resulted in a shared blood supply with younger mice. In addition, recently developed functional MRI techniques offer both new diagnostic and therapy monitoring capacities. All of these advances will benefit from the enhanced communication and analysis offered by JAD to researchers and clinicians working on Alzheimer's disease.

Given the JAD's performance and steadfast respect for its founding goals to facilitate communication of 
new and original ideas and results, we offer our humble thanks and admiration and wishes for the continued success for the Journal of Alzheimer's Disease.

Founding Editor-in-Chief, Carl R. Merril, M.D. (E-mail: merrilcarl@msn.com.)

Founding Supporter, Hossein A. Ghanbari, Ph.D.

( E-mail: hghanbari9@gmail.com.)

\section{DISCLOSURE STATEMENT}

Authors' disclosures available online (http://j-alz. com/manuscript-disclosures/14-2263). 